\title{
Study on the Individualism in American Westward Movement and Collectivism in Chinese Western Development
}

\author{
Wang Hui \\ College of Liberal Arts, Xi'an International University, Xi'an Shaanxi, China 710077
}

Keywords: American Westward Movement, Chinese Western Development, Individualism

\begin{abstract}
With the increasingly frequent cultural exchanges between China and the United States, it is necessary for us to know the cultural differences between China and the United States in consciousness. In this thesis, the author made a historical exploration of the special period of the American ideology in the westward movement and the collectivism shown by the Chinese in the western development, which can help people to study the different history of cultural differences from a historical point of view. Besides, by making a study of Chinese collectivism and western individualism in a defined time frame, people of America and China could perceive, understand and tolerate various deep structures of both cultures, and have a clear understanding of the customs behind the culture which have shaped their personal mindsets and values. Already-accepted values of culture as a kind of spiritual culture shared by all the people greatly promote the cross-cultural communication among people around the world.
\end{abstract}

\section{Introduction}

Living in a time of rapid change, we have to rethink cultural struggles and identities. It may be difficult for us to envision, but through westward expansion, Americans have occupied a dominant position in the western hemisphere, with vast territories stretching from the Atlantic Ocean to the Pacific. It is an incontestable time that American people tried to achieve their American dream on the newly discovered land. The idea of the American Dream is rooted in the Declaration of Independence, which proclaims that "all men are created equal" and that they are "endowed by their Creator with certain inalienable Rights" including "Life, Liberty and the pursuit of Happiness." That is to say, each individual was inspired to contribute their painstakingly effort to their survival, which was significant not just for them but for the independence and rise of a new country as a whole.

According to Webster's New Collegiate Dictionary, individualism conduct and practice guided by such a theory. The pursuit of individual rights and interests is considered utterly legitimate. Self-actualization and the maximal realization of individual potential are supreme aims in life. So they regard human being as the most important among all valuable things and believe that individual is the primary unit of reality and the ultimate standard of value. Individualists believes that every person is an end in him and that no one should be sacrificed for the sake of another.

Whereas, collectivism holds that the group, the nation, the community and the race are the primary unit of reality and the ultimate standard of life. This view does not deny the reality of the individual. It merely deems that the individual should be submitted to the collective.

The essential difference between individualism and collectivism is mainly expounded from 6 aspects: meaning, condition, class nature, economic foundation, content and function. Specific descriptions of the various aspects are as follows:

(1) Differences in Meaning

Collectivism is a kind of value, which takes the interests of the people as the fundamental starting point of selfless thoughts, and political principles and moral principles of the nation. Individualism is an ideological system with the values centered on individuals at the expense of the interests of society and others to meet individual desires. 
(2) Differences in Production Conditions

Collectivism is gradually formed and developed in the struggle of the proletariat. While individualism is formed with the development of capitalist relations of production and in the process of opposing feudal autocracy and religious theology.

(3) Differences in Class Nature

Collectivism is the core of proletarian outlook on life. And individualism is the core of the bourgeois outlook on life.

(4) Differences in Economic Base

Collectivism is based on the public ownership of the means of production and serves for the consolidation and development of the public sector of the economy. Individualism is adapted to the economic system of the western capitalist countries and serves the fundamental interests of the bourgeoisie.

(5) Differences in the Content

The main content collectivism is: adhering to the combination of collective interests individual interests to promote the harmonious development of the society, advocating putting the national and collective interests in the first place, fully respecting and safeguard the legitimate interests of individuals and their personal initiative. If there is a conflict between the interests of the state, collective and individual, personal interests should give way to the national and collective interests. While individualism is a kind of value system, which puts the interests of each individual before others, with the state and others as a means to achieve personal goal.

(6) Differences in the Role

Collectivism is the guarantee for the the victory of the proletarian revolution socialist construction. It is the correct value orientation of Chinese people in the new period. And individualism has once played an positive role in opposition to feudal dictatorship and religious theology, but it has such obvious limitations as corrupting people's thoughts, arousing cruel struggle between people, endangering social stability and leads to the belief crisis of collectivism.

\section{Core Elements of Individualism in American Westward Movement}

Individualism emerged unmistakably when the earliest settlers come to North America to escape the fierce religious persecution of the Puritans. In 1602, the famous "Mayflower"ship moored this land. It is a time that individualism was highlighted to its biggest possibilities. And it was strengthened in the extensive explosion of the West. In the campaign, millions of the labor masses endured hardship in pioneer work, they had created enormous material and spiritual wealth. As a result, people in modern times deem the eighteenth century as the heyday of individualism for its normalization. Moreover, in American's society, opportunity, self-reliance, independence and competition have the tightest link with individualism.

The United States witnessed a dramatic change of the meaning of individualism due to the development of American history. The westward expansion has often been regarded as the central theme of American history, down to the $19^{\text {th }}$ century and as the main factor in the shaping of American character. The earliest settlers came to the North American continent to establish colonies, which were free from the controls that existed in Europe. In 1776, the British settlers declared their independence from England and established a new nation, the United States of America. By limiting the power of the government and the churches and eliminating a formal aristocracy, the settles created a climate of freedom where the emphasis settlers were on the individual. The United States come to be associated in their minds with the concept of individualism. In addition, the concept involves freedom, opportunity, self-reliance, self-improvement and self-help. This is probably the most basic of all American values.

With the "principle of priority" dominating social environment, people's hierarchy gradually disappeared. Dispensing with the stereotype of being traditionally classified into aristocracy and populace, the motivation was spurred spiritually. Up until then, people were conscious of striving for themselves truly. For most of them, went into the west then moved towards the future. West is the palace of freedom, for people pay high attention to the individual freedom, emphasizing 
self-control and self-control without abroad constraint. Opportunity equally shows in front of individuals, including other westerners. In fact, people's purpose going to the west was similar.

No matter rich or poor, educated or uneducated, they squeezed in a caravan or a steamboat, without distinction. In a sense, the American government was behind the large-scale migration. In order to drive the movement, the federal government carried out the free migration policy, encouraging foreigners to move to America, besides, an unprecedented trans-regional migration happened in America from 1790 to 1910, the population center moved 557 miles westward. During regional development, the government creates the opportunities by building the transportation profoundly, which conveniently connected the whole country.

In my eyes, it is not so much a way of expansion as a strategy to create job opportunities to the migration in the rugged and primitive area. Transportation facilitated western economy as well as the growth of the north economy. it will have their main effect many years hence. The infrastructure of school, hospital and railway will benefit people in this area in the long run.

Individuals must learn to rely on themselves or risk losing freedom. This strong belief in self-reliance continues today as a traditional basic American value.

In 1784, 1785 and 1787, the federal government made up three land acts, establishing three principles of dealing with western lands for the first time in American history. Lincoln government issued the Homestead Act, arousing people's enthusiasm for the Westward Movement. To strengthen agricultural management as well as the development of agricultural technology. It is not as easy as we imagined exploiting an extended land. Needless to say, the passion for a better life in the land morally supports them to surmount all the difficulties.

In 1790, the total population of the United States was nearly four million people and farmers made up about $90 \%$ of the labor force. A belief in the inherent virtue of rural life and farm labor was a prevalent concept in the new nation. Thomas Jefferson championed the agrarian ideal, stating in his Notes on Virginia in the 1780s that "Those who labor in the earth are the chosen people of God.

Generally speaking, the naturally arid weather of the west is not proper for the cultivation. Nevertheless, as we always say god helps those who help themselves. The diversity of crops and livestock was raised in the West, including vegetables, wheat, fruits, cattle, and ostriches. For the farmer of the land, they made it by their individual effort.

"We hold these truth to be self-evident, that all man are created equal, that all they are endowed by their Creator with certain unalienable rights, and among these are life, liberty and the pursuit of happiness.” from the Declaration of Independence.

Originally, it highly emphasizes one should make Judgments dependent on his own will alone. As far as education is concerned, in the early times, in developing a sense of self-hood and independence. For instance, the United States is made up of fifty individual states according to the Constitution for the purpose of interaction and the respect of each state's initial uniqueness. As a result, the United States is made up of fifty individual states according to the Constitution for the purpose of interaction and the respect of each state's initial uniqueness.

\section{Collectivism in China}

The Chinese culture measures very high on the "collectivism” scale along with Japan and Korea compared to most Western cultures. This means that the Chinese, in general, act as a collective society that strives for harmony and group belonging, whether to family, friends, work, or country.

In the east, Confucius is considered as the greatest saint. He is the major founder of our profound traditional Chinese culture. Confucianism, established and developed by one of his followers, has had a significant influence on the formation of Chinese national characteristics. For the historical reason,

Collectivism is inherent in a Confucian society. In order for Chinese society to operate smoothly, it was necessary to subject one's own desires to the greater good of the group. In other words, people didn't exist independently of one another. Instead, an individual was defined by his or her relationship to the group.

The Western Development, launched in 2000 by the Chinese Government, will greatly improve 
the standard of living of the 355 million people living in the west of China. The project aims at accelerating the development of the western region and narrowing down the gap between the less developed western region and the well-developed eastern coastal region. Based on concept of collectivism, the sense of team spirit was strongly advocated by the Chinese government. Under the background of the western development, a series of actions, policies and measures have been carried out for sustainable support.

As mentioned in the definition of collectivism, in collectivism culture individuals subordinate their personal goals to the goals of the collective. Cases in this point are Natural Forest Conservation Program and the Grain to Green Program, which emphasizes expansion of natural forests and increasing the productivity of forest plantations. This new policy is being implemented with a new combination of policy tools, including technical training and education, land management planning. Such ecological programs certainly have great impact on the social-economic live hoods of peasant; however, considering the efficient development of this area, the group interests take priority over each individual again. Farmers give up their rights of arable land to support the programme, which fully embodies the spirit of sacrifice self-interests for the whole. Farmers make way for the government out of the value of collectivism. It is a good illustration for the "all for one, one for all".

Our progress as a nation can be no swifter than our progress in education. the human mind is our fundamental resource." by John F. Kennedy. From this view, we may know that education for all means has been the most important role in all the stages of an ever progressing and developing society, equally for the west or the east. For the progress of a nation, it will not be wise to neglect the importance of education for the development of society as a whole. It has led to the development of many government-aided educational programs and government grants to schools and colleges.

In China, heaps and heaps college graduates are joining in the Volunteer Teachings in the West under the call of the government. For these students themselves, it is a good chance to experience life in the lesser developed areas. For example, in 2011, a group of seventeen postgraduate students from Peking University will spend one year as teaching volunteers in the country's remote and underdeveloped western regions starting in August. This will be the 13th such team that the university, famed for excellency in humanities and social sciences, has sent student volunteers to teach for one year in Tibet, Qinghai, Yunnan, Xinjiang, Ningxia, Shanxi and Henan of central and western China since 1999. The students are the epitome of the traditional value of collectivism. They think a lot of the devoting spirit of individual for the collective benefits.

The preferential policies are largely "deregulation policies" that enabled marketization and internationalization of the western economy and allowed the area to become equally developed. From the time of Reform and Opening Policy, the economic disparity between larger and larger because of east-leaning sectional policy. Now, as for the west, government has attached importance to the economy of the western region.

Taking the Qinghai-Tibet Railway as a case, the line was built during Chian's Tenth 5-Year Plan and in China, is considered a land-market project. It is the world's highest railway, extending over $1956 \mathrm{~km}$ from Xining to Tibet Autonomous Region. The Chinese government has invested an unprecedented amount of money to boost the economy of this area. The Qinghai-Tibet Railway will also promote local tourism and related economic development. Regional authorities estimate that by 2015, the number of tourists will double from the 2008 total of 3.2 million, and tourist revenues in the region will rise to 6.8 billion yuan per year. From the accurate data and analyzing situations, the Qinghai-Tibet Railway will ultimately promote the sustainable ecological, social, and economic development of western China.

America is the typical representative of individualism and China is that of collectivism. Although, there are many differences between America and China in various ways, people in the two nations hold the same objective. No matter for the American Westward Movement or for the Chinese Western Development, the main objective is to boost and balance the economy in different areas of their country. Holding their own values, the people in these two countries spear no effort to the 
national development and ultimately achieve their goals for their own good.

A good understanding of such a difference will help us have a proper grasp of the culture of the two countries and do cross-culture communication successfully. The biggest difference between individualism and collectivism lies in their different perspectives viewing things.

An essential attribute of individualism culture is that the individuals are not apt to subordinate their goals to the goals of the collective. Furthermore, the individuals may put more efforts on the achievement of their respective goals.

On the contrary, in collective culture, maximizing the group's interest over the minority is one of the significant concepts. As the case of Chinese Western Development mentioned above, the farmers' giving up the arable land for the environmental program in the long term is the best proof.

\section{Conclusion}

In summary, the findings indicate that individualism is associated with attention to individualized activities and that collectivism is associated with attention to shared pursuits. As Douglas C.D. Pecock argues, “...human identity presupposes the identity of the special period," the place is the important foundation for an individual to form one's identity. To study a period in history, therefore, means to study the people and their values in the period.

With all these reasons being into contemplated, it can be safely concluded that the value of one culture is the coherent, learned, shared view and value of a group of people's concern about their lives. Although research on individualism and collectivism has not yet examined situations on the modern times, but by tracing back to its originally historical moment, revealing the arcane background and the complicated historical reasons, we can analyze the relations objectively. In addition, along with the rapid globalization and the more frequent cultural communication, it is indispensable for people to make full preparation for it. With a good understanding of culture, especially its value, the cultural communication will be more harmonious and beneficial. People's thinking can adjust accordingly to the situation.

\section{References}

[1] Justin Winsor. The Westward Moment by Justin Winsor. Oxford University Press, 2014.

[2] Li, Q iron g. On the Lesson of the U.S. Westward Movement. Journal if Huazhong Normal university, 2006.

[3] David M. Kennedy, Lizabeth Cohen, Thomas A.Baliey. The American Pageant. Oxford university press.

[4] Jdith N. Martin, Thomas K. Nakayama. Experiencing Intercultural Communication. Arizona State University, 2003. 